\title{
INNOVATIVE APPROACH TO AGRICULTURAL MACHINERY TESTING
}

\author{
Nikolay Artiomov ${ }^{1}$, Roman Antoshchenkov ${ }^{1}$, Viktor Antoshchenkov ${ }^{1}$, Abdulmelik Ayubov ${ }^{2}$ \\ ${ }^{1}$ Kharkiv Petro Vasylenko National Technical University of Agriculture, Ukraine; \\ ${ }^{2}$ Tavria State Agrotechnological University, Ukraine \\ artiomovprof@ukr.net, roman.antoshchenkov@gmail.com, viktor.tiaxntusg@gmail.com, \\ mvz@tsatu.edu.ua
}

\begin{abstract}
For qualimetric tests of mobile machines and agricultural units without making changes to the design and suspending the performance of agrotechnical operations, it is necessary to apply new modern methods and measuring instruments. In the context of the intensification of agricultural production, the issue of creating mobile registration and measuring complexes for assessing the parameters of the movement of agricultural units during qualimetric tests is relevant. Accelerometers are the main element in the registration and measurement complexes developed by the university scientists. They are widely used in the automotive industry in assessing aerodynamic and traction-speed properties, braking properties, handling and stability, smooth running, noise and vibration, reliability, and passive safety. In the first version of the measuring complex, microelectromechanical systems (MEMS) technologies were used. The development of the measuring complex has become a measuring system for the dynamics and energy of multi-element agricultural units. The developed measuring system belongs to the technical means of diagnostics and operational control. It can be used in agriculture and engineering industries. The system is designed to determine the kinematic, dynamic, power and energy characteristics of mobile machines and their elements during road, field and bench tests. The measuring system includes inertial measuring devices consisting of gyroscopes, acceleration sensors and magnetometers, a navigation receiver, rotation speed sensors, electronic dynamometers, analogue and discrete inputs, a fuel flow sensor and wheel dynamics sensors. An innovative component of the measuring system is the way to detect slippage of wheels or drive sprockets. It consists of determining the wheel speed using a wheel dynamics sensor, which includes a gyroscope, accelerometer and magnetometer mounted in the centre of the wheel.
\end{abstract}

Keywords: measuring complex, microelectromechanical systems, agricultural machinery.

\section{Introduction}

The operation of the tractor unit calls for a variety of modes and a large number of technological processes. Automatic devices are created for finished tractors and machines aggregated with them. However, qualitatively complex automation of the unit can be carried out only at joint development of the system "tractor - tool - automatic machine", the possibility of change in technology of agricultural operations being not excluded.

The problem of substantiation of optimal operating modes and parameters of tractors is of great importance. Existing calculation methods do not allow to determine them with the required accuracy. The diversity of soils and a large number of other factors make the solution of this problem more complicated.

To ensure the continuity of the technological process and increase the accuracy of experimental data, measuring systems based on three-axis accelerometers were developed, the operation of which is based on the MEMS technology.

\section{Materials and methods}

An accelerometer is a miniature sensor changing its properties under the action of acceleration. It can be an analog device, a piezoelectric sensor or an element of variable capacity - a capacitor with a movable cover. The accelerometer generates a small voltage at its electrodes, which can be measured and converted into acceleration. Nowadays, MEMS devices are used almost everywhere. As microelectronics develops, various miniature sensors appear [1;2]. A separate group of such sensors is called MEMS - micro electromechanical sensors. Acceleration sensors - accelerometers are used to measure movements.

The rapid development of MEMS technologies is largely due to their key advantages, that is a small size, functionality, reliability, low power consumption, ease of integration and demand at almost all electronics markets.

The task of measuring linear accelerations and related tasks of controlling the position of the object in space, speed, vibration and other characteristics is relevant in many areas of the national economy 
and operation of machines and units. Clearly, to solve such a common problem a wide range of specialized sensors - accelerometers - with a variety of characteristics, both in terms of measurement ability and resistance to external influences, and the range of operating conditions and reliability are provided [3].

\section{Measuring complex}

To conduct dynamic and qualimetric tests at the Department of Tractors and Automobiles of the Kharkiv P. Vasylenko National Technical University of Agriculture together with the Department of Repair Technology of the Kharkiv National Automobile and Road University, a registration and measuring complex (Fig. 1) was created on the basis of three-axis accelerometers [4].

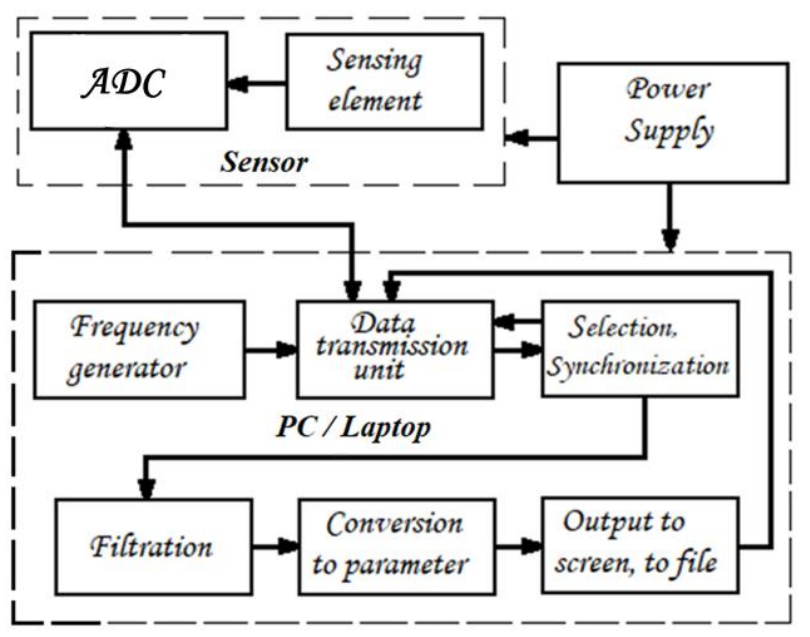

Fig. 1. Block diagram of the registration and measuring complex

The most important requirement for MEMS of mass application is the positive cost-performance ratio, and for that for special purpose devices is their high performance. The advent of MEMS technology has made it possible to conduct experimental studies of agricultural machinery and has become a unique, simple solution to many previously complex system problems of monitoring and control not only because of their merits, including the ease of integrating a miniature component into a client's system.

The motion of a tractor unit, taking into account the assumption that its mass is concentrated in the kinematic center, can be considered to consist of the motion of the center of mass and the motion around it. The first type of movement usually characterizes the translational movement of the unit and is determined mainly by its load modes. The second type characterizes the deviation of the direction of movement from the specified and is determined mainly by the ability of the unit to maintain this direction when performing a certain technological process $[5,6]$.

The change in the sum of forces characterizes the load regime, technical condition and functional stability of the unit, which occur in the process of performing the technological operation:

$$
\frac{d v}{d t}=\frac{P_{k}-\sum P_{r}}{m_{t u}},
$$

where $\quad v$-speed of the machine-tractor unit, $\mathrm{m} \cdot \mathrm{s}^{-1}$;

$P_{k}-$ driving force of the unit (tangential traction force), N;

$\Sigma P_{r}-$ sum of all forces of resistance to the movement of the unit, $\mathrm{N}$;

$m_{t u}-$ mass of the tractor unit reduced to translationally moving parts, $\mathrm{kg}$.

In the equation with sufficient approximation we can assume the reduced mass of the machinetractor unit as a constant $\left(m_{t u}=\right.$ const $)$. The forces of resistance to the movement of the unit during operation depend on factors, many of which are variables, such as the soil condition, terrain and technical condition of the unit, physical and mechanical properties of the cultivated soil, tillage depth, speed, etc. In accordance with the change of resistance forces, the driving force of the unit also changes. 
All this leads to the fact that, when a machine-tractor unit performs a certain technological process, $d v / d t$ is constantly changing both in size and in sign.

The forces of resistance to the movement of the unit primarily depend on the speed. We will further consider this dependence to be a continuous function and, thus, it can be linearized [7].

The driving force of the unit with a sufficient approximation can be considered as a continuous function of speed, which can be written in the form:

$$
P_{k}=P_{k s}+\frac{\partial P_{k}}{\partial v} \Delta v+\Delta P_{k 1},
$$

where $P_{k s}-$ steady value of the driving force of the unit, $\mathrm{N}$;

$\partial P_{k} / \partial v$ - value of the derivative at the point of steady mode of motion;

$\Delta P_{k 1}$ - change in the driving force due to the influence of all factors except the speed, $\mathrm{N}$.

The forces of resistance to the movement of the unit can be represented by the following expression:

$$
\sum P_{r}=\sum P_{s r}+\frac{\partial \sum P_{r}}{\partial v} \Delta v+\Delta \sum P_{r 1},
$$

where $\sum P_{s r}-$ steady value of the resistance, $\mathrm{N}$;

$\frac{\partial \sum P_{r}}{\partial v}-$ value of the derivative at the point of steady motion of the unit;

$\Delta \sum P_{r 1}$ - change in the strength of resistance, depending on the terrain, $\mathrm{N}$.

The change in the sum of forces characterizing the technical condition and functional stability of the machine occurs when the unit performs a technological operation.

The equation (1) taking into account possible external perturbations will take the form:

$$
, \frac{d v}{d t}=\frac{P_{k}-\Sigma P_{r} \pm P_{\text {perturb }}^{\text {extern }}}{m_{t u}}
$$

where $P_{\text {pertub }}^{\text {extern }}-$ external perturbing force, N.

Dividing equation (4) by $m_{t u}$ transforming it into the equation of partial accelerations [4], the equation will take the form:

$$
\frac{d v}{d t}=\dot{v}_{\kappa}^{p a r t}+\dot{v}_{c}^{\text {part }}+\dot{v}_{p e r t u b}^{p a r t}-\frac{v}{m_{t u}} \cdot \frac{d m}{d t}
$$

where $\quad \dot{v}_{\kappa}^{\text {part }}-$ partial acceleration of driving forces, $\mathrm{m} \cdot \mathrm{s}^{-12}$;

$$
\dot{v}_{K}^{\text {napu }}=-\frac{P_{k}}{m_{a 2}} ;
$$

$\dot{v}_{r}^{\text {part }}$ - partial acceleration of resistance forces, $\mathrm{m} \cdot \mathrm{s}^{-12}$;

$$
\dot{v}_{r}^{\text {part }}=-\frac{\sum P_{r}}{m_{t u}} ;
$$

$\dot{\mathcal{V}}_{\text {pertub }}^{\text {part }}-$ partial acceleration of external perturbing forces, $\mathrm{m} \cdot \mathrm{s}^{-12}$;

$$
\dot{v}_{\text {pertub }}^{\text {part }}=\frac{P_{\text {pertub }}^{\text {extern }}}{m_{t u}} .
$$




\section{Measuring system for the dynamics and energy of mobile machines}

The measuring complex evolved into the measuring system of dynamics and energy of multielement agricultural machinery. The measuring system for the dynamics and energy of mobile machines has been developed for experimental research [8; 9]. This system belongs to technical means of diagnostics and operational control and can be used in agriculture and the machine-building industry. The measuring system is designed to determine the kinematic, dynamic, power and energy characteristics of mobile machines and their elements during road, field and bench tests.

The main components of the measuring system are: computing module; sensors; power supply.

The system is used to determine the dynamic and energy properties of trucks and cars, buses and road trains, tractors, military wheeled and tracked vehicles, as well as their elements in operation, during auto technical examination and in other cases requiring operational control of the machine (Fig. 2).

The system determines the linear accelerations and angular speeds around the axes of symmetry of the mobile machine, translational speed, geographical position, fuel consumption, traction force, wheel speeds and other parameters.

A wheel dynamics sensor for a mobile machine has been developed, which consists of three axial accelerometers and a magnetometer, as well as three axial gyroscopes (Fig. 3). The sensor is an inertial measuring device that is assembled on the basis of a microcontroller. The microcontroller transmits data on the $2.4 \mathrm{GHz}$ channel via the radio module. The sensor contains a battery. It determines the speed of rotation of the wheel of a mobile machine (tractor or car) or the drive sprocket of a caterpillar tractor. It enables us to determine the actual speed of rotation of the wheel, its orientation in space without interfering with its design.

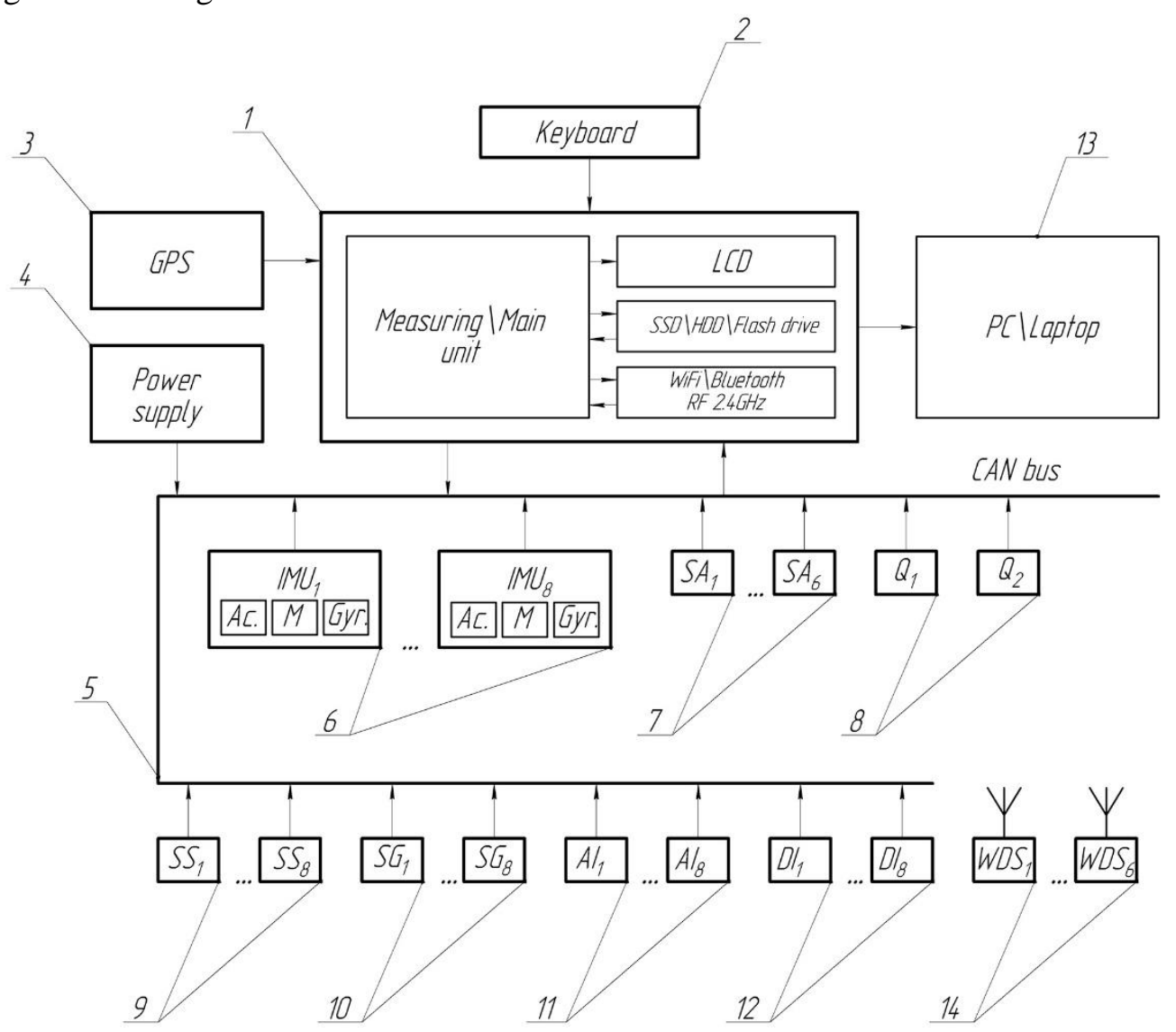

Fig. 2. Block diagram of the measuring system of dynamics and energy of mobile machines:

1 - computing module; 2 - keyboard; 3 - GPS receiver; 4 - power supply; 5 - CAN data bus;

6 - inertial measuring device; 7 - angle encoder; 8 - fuel flow meter; 9 - speed sensor (rotation 
speed); 10 - electronic dynamometer; 11 - analog inputs; 12 - discrete inputs; 13 - computer; 14 - wheel dynamics sensor

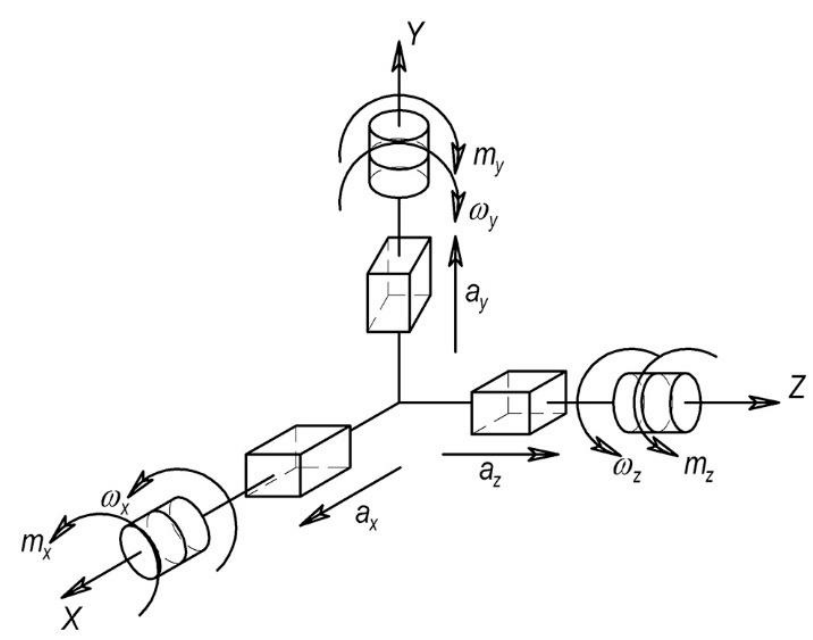

Fig. 3. Structure of the wheel dynamics sensor: $a_{x}, a_{y}, a_{z}$-acceleration sensors (accelerometers) on $x, y, z$ axes; $\omega_{x}, \omega_{y}, \omega_{z}-$ angular velocity sensors (gyroscopes) on $x, y, z$ axes; $m_{x}, m_{y}, m_{z}$ - magnetic field strength sensors (magnetometers) on $x, y, z$ axes

The speed of rotation of the wheels is determined using a gyroscope $\omega_{z}$ and an accelerometer $a_{z}$. The angular velocity is measured by the gyroscope and equal to the angular velocity of rotation of the wheel $\omega_{z}=\omega_{\kappa}$. As the wheel rotates, the accelerometer signal $a_{z}$ changes harmonically, and the frequency of this signal is equal to the angular speed of rotation of the wheel $\omega_{\kappa}=f\left(a_{z}\right)$. Wheel skidding is determined by [10]:

$$
\delta=\frac{2 \cdot \pi \cdot r_{\partial} \cdot n_{w}-v_{\partial}}{v_{\partial}} \cdot 100 \%
$$

where $\delta$-wheel skidding, \%;

$n_{w}$ - rotation frequency of the wheel, determined by the sensor, rps;

$r_{\partial}-$ wheel radius, determined according to ISO 4251-1:1992, $\mathrm{m}$;

$v_{\partial}-$ actual speed determined by the GPS receiver, $\mathrm{m} \cdot \mathrm{s}^{-1}$.

\section{Results and discussion}

The measuring complex has obtained the dependence of the longitudinal acceleration of the tractor BELARUS-80.1 on time (Fig. 4).

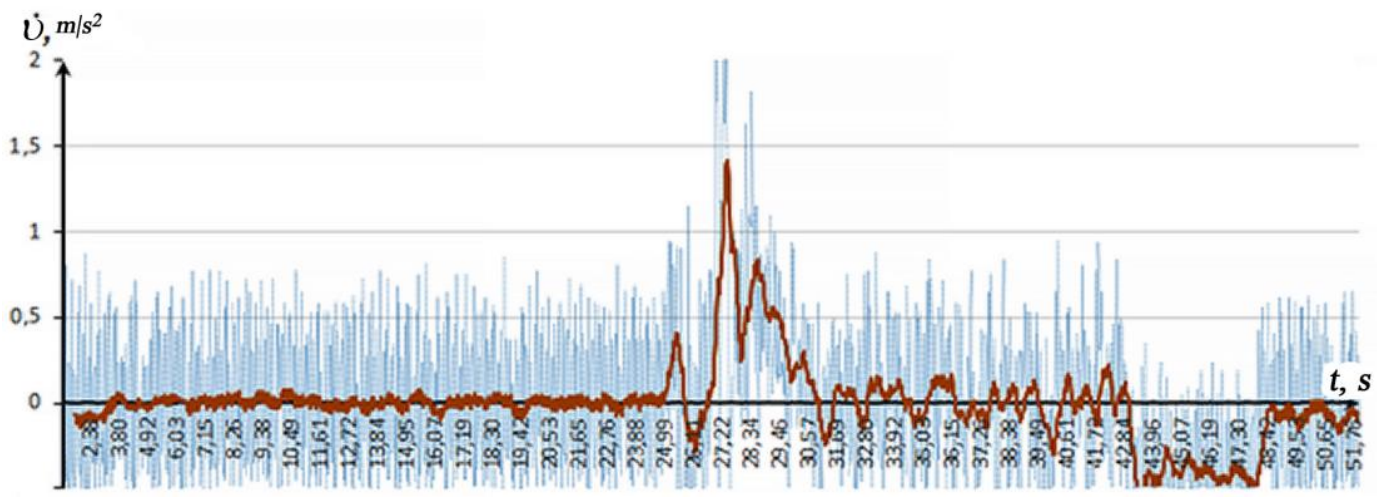

Fig. 4. Dependence of longitudinal acceleration of the tractor BELARUS-80.1 on time

Based on the results of the experimental studies with the application of the measuring system and theoretical calculations, we construct the difference between the calculated and measured thrust as a function of time (Fig. 5). 
The smallest value of the difference between the calculated $T_{c}$ and the measured $T_{m}$ of the thrust force of the BELARUS-80.1 tractor is $200 \mathrm{~N}$, and the largest is $500 \mathrm{~N}$ (Fig. 5).

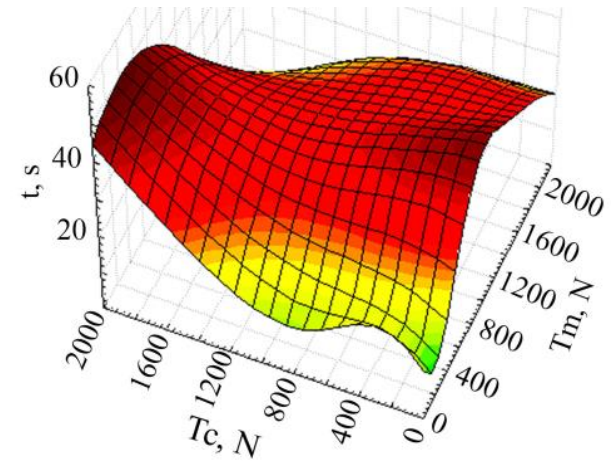

Fig. 5. Comparison of the calculated $T_{c}$ and the measured $T_{m}$ thrust force of the tractor BELARUS-80.1

The dependence of skidding of driving wheels on time has been experimentally determined for the tractor BELARUS-80.1 by the measuring system for the dynamics and energy of mobile machines (Fig. 6).

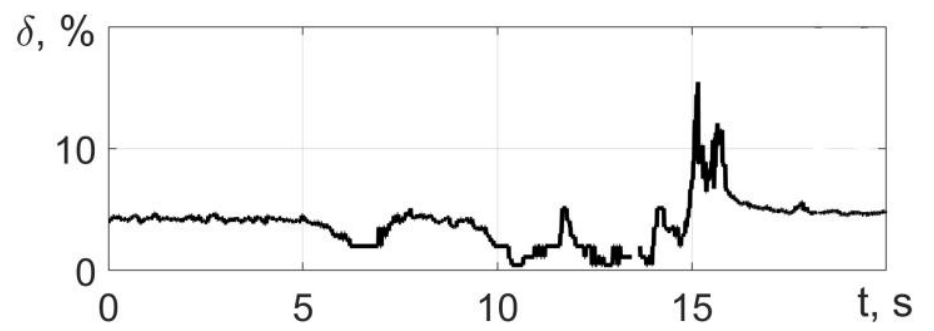

Fig. 6. Dependence of skidding of driving wheels of the tractor BELARUS-80.1 on time

The average value of skidding of the driving wheels of the tractor BELARUS-80.1 is determined at the level $\delta=5 \%$, i.e. low enough for this tractor.

An innovative approach to testing agricultural units is to use the original developed methods for assessing the tractive effort of a machine by its accelerations, as well as the use of measuring systems to measure accelerations.

\section{Conclusions}

1. The application of the registration and measuring complex allows to carry out dynamic and qualimetric tests of agricultural machinery without interference into its design and provides continuity of performance of agrotechnical operation. Based on the results of the experimental studies with the application of the measuring system and theoretical calculations, the difference between the calculated and measured thrust of the tractor BELARUS-80.1 was determined. The smallest value of the difference is $200 \mathrm{~N}$, and the largest is $500 \mathrm{~N}$.

2. The evolution of the measuring complex emerged in the measuring system of dynamics and energy of multi-element agricultural machinery. A wheel dynamics sensor for a mobile machine has been developed for the measuring system, which consists of three axial accelerometers and a magnetometer, as well as three axial gyroscopes. The sensor determines the average value of skidding of the driving wheels of the tractor BELARUS-80.1, which is at the level $\delta=5 \%$, i.e. low enough for this tractor.

\section{References}

[1] Aleksiiev O.P., Aleksiiev V.O., Klets D.M., Artiomov M.P., Kurenko O.B., Rohozin I.V., Novychonok S.M., Khabarov V.O., Kruk B.M.. Development of automotive computer systems based on the virtualization of transportation processes management. Eastern-European Journal of Enterprise Technologies. vol. 6/3(90), 2017. pp. 14-25. 
[2] Eloe J.C. MEMS and Nano Divergence: Status of MEMS industry. Yole development, 2009.107 p.

[3] Тузов А. Датчики для измерения параметров движения на основе MEMS-технологии. Часть 1. Инерциальные датчики средней точности. (Sensors for measuring motion parameters based on MEMS technology. Part 1. Inertial sensors of average accuracy.) - Электроника: НТБ, 2010, № 1. c. 72. (In Russian).

[4] Artiomov M., Klets D., Boldovskyi V., Makovetskyi A., Kostyk K.. The influence of the driving speed and vertical acceleration of the mobile machine on the change of soil packing. International Journal of Engineering \& Technology, 2018. pp. 1-6.

[5] Коденко Н.М., Лебедев А.Т. Автоматизация тракторных агрегатов (Automation of tractor units). М.: Машиностроение, 1969. 196 с. (In Russian).

[6] Адамчук В.В., Булгаков В.М. Пріоритетні напрями створення сучасної сільськогосподарської техніки (Priority areas for the creation of modern agricultural machinery). Вісник аграрної науки, 2014. № 5. с. 5-11. (In Ukrainian).

[7] Tayanowskiy G., Wojciech T. Tractor vibration dynamics evaluation in an aspect of the possibility of coupling and of loading its driving axle. Motrol, 2006. vol. 8A. pp. 271-279.

[8] Bulgakov V., Ivanovs S., Adamchuk V., Antoshchenkov R. Investigations of the Dynamics of a Four-Element Machine-and-Tractor Aggregate. Acta Technologica Agriculturae, 2019. vol. 22/4. pp. 146-151.

[9] Dzyuba O., Dzyuba A., Polyakov A., Volokh V., Antoshchenkov R., Mihailov A. Studying the influence of structural-mode parameters on energy efficiency of the plough PLN-3-35. EasternEuropean Journal of Enterprise Technologies, 2019. vol. 3/1 (99). pp. 55-65.

[10] Melnik V., Antoshchenkov R., Antoshchenkov V. Determination of Mobile Machine Wheel Dynamics. Control and Signal Processing Applications for Mobile and Aerial Robotic Systems. Robotics and Autonomous Systems, 2019. vol. 3. pp. 1-25. 